\title{
Annular closure devices-here to stay or here to go?
}

\author{
Vitor Castro ${ }^{1} \cdot$ Manuel Cunha e Sa ${ }^{1}$ (D) \\ Received: 3 October 2020 / Accepted: 6 October 2020 / Published online: 16 October 2020 \\ (C) Springer-Verlag GmbH Austria, part of Springer Nature 2020
}

The bulk of the information regarding the use of annular closure devices in the prevention of recurrent herniation following lumbar discectomy comes from a randomized clinical trial (RCT) to evaluate the use of Barricaid device (Barricaid, Intrinsic Therapeutics, Inc, Woburn, MA) [9]. Previously reported long-term outcomes (3 years) of this RCT have shown a significant decrease in symptomatic reherniation (14.8 vs $29.5 \%$ ) and reoperation (11 vs $19.3 \%$ ) rates when compared with the control group [4]. This translates to 7 patients needed to treat to prevent one reherniation and 12 to prevent one reoperation. These are promising results by any measure.

As in any innovative therapeutic intervention, the results obtained matter as much as the toll 'paid' in achieving them. Published in the current issue of Acta Neurochirurgica, the paper 'Intraoperative findings, complications, and short-term results after lumbar microdiscectomy with or without implantation of annular closure device' addresses this question by evaluating the safety and perioperative complication profile of this relatively new device, with data collected from patients included in this RCT.

The authors report that from a total of 276 patients randomized to the annular closure device (ACD), 5 patients failed implantation because of technical difficulties, and another 4 having local anatomy that prevented the device from being safely implanted; technical difficulty in implanting the device was reported as acceptable in $28.4 \%$ and hard/difficult in 7.8\%; surgical time and blood loss were significantly higher in the ACD group; dural tears in the ACD group were 4.8 vs 2.5\%; there was 1 nerve root avulsion in the ACD group, a major event with serious nefarious effect on the patient that cannot be understated; device migration occurred in 5 patients with 2 patients requiring reoperation for correction/removal in the first 3 months post op. Despite this, device and procedure-

This article is part of the Topical Collection on Spine degenerative

Manuel Cunha e Sa

mcunhaesa@gmail.com

1 Hospital Garcia de Orta, Almada, Portugal related adverse events in the 3 months post op were reported at $3.7 \%$ in the ACD group vs $7.9 \%$ in the control group (if reherniation is excluded, the number of adverse events is evened between the groups).

While these results suggest that the perioperative complications are globally comparable between the two groups, they also show that this is a technically more demanding surgery, with several anatomical considerations and limitations (as seen by the 9 patients in which it was not possible to implant the device) and increased likelihood of intraoperative complications (represented by the nerve root avulsion and higher incidence in dural tears). This is carefully commented by the authors, whose personal and institutional use of this device has been put on hold pending further data and clarification. One also needs to keep in mind this clinical trial was based on high-volume spine surgery centres and surgeons, which might make these results difficult to generalize for lower-volume centres while keeping the same safety/complications profile.

Regarding the safety and durability of the device itself after implantation, the results suggest that failures with clinical significance occur throughout the follow-up period, with 2 patients $(0.74 \%)$ being reoperated at 3 months and $12(4.4 \%)$ at 3 years. This should be emphasized, because the maximum effect of preventing reherniation seems to be at around 1-year follow-up, after which the reherniation rates tend to equalize. After this period, the difference between reoperation rates seems to stabilize or even diminish between the 2 groups [6]. This might be a result of implant degradation/failure requiring revision surgery, but with the limited data available so far, this is purely speculative at this point.

Although degenerative disc disease (evaluated by disc height and vertebral endplate changes) has been noticed to progress in higher degree in the ACD group, the clinical significance of this radiological findings seems to be elusive so far, as the clinical outcomes do not differ between the groups $[1,5]$. This may be a secondary biomechanical effect after the implantation of the device in the disc space, but this hypothesis needs further testing and longer follow-up to assess possible clinical effects. 
It is never enough to stress that these results have been obtained in a very selected subgroup of patients surgically treated for lumbar disc herniation, namely, the ones with annular defects between $4-6 \mathrm{~mm}$ in height and $6-10 \mathrm{~mm}$ in length after limited discectomy, patients in which a higher rate of recurrence has been shown to occur. In lower-risk patients, the benefit might not be so pronounced and a larger amount of patients treated may be required in order to justify the device implantation, both from a clinical and economical standpoint. If a more widespread adoption of this device will ensue, it will be very important that strict adherence to the indications and technical nuances be respected in order to maintain the efficacy/safety profile shown in the RCT.

In our opinion, this device is based on the assumption that re-herniation is, at least in the current state of the art, an unpredictable phenomenon, resulting from a mix of mechanical, inflammatory, degenerative, genetic and social factors, which makes its prevention a rather difficult aim to secure. From a conceptual point of view, the perspective of tying it down to the height of the disc and the size of the annular hole is the logical corollary of a simplistic interpretation of the occurrence. Of course the more disc material remains in the disc and the wider the gaping exit route into the canal, the higher the chance that recurrence of herniation may occur. However this likelihood is interfered by many other random factors to the point that those two above variables may only represent the tip of a much bigger and complex iceberg. To name but a few that immediately come to mind, one would invoke the weight, the age and the professional/sportive demeanour of the patient, the looks of the disc on MRI, the presence of low back pain as well as the state of the lordosis at the diseased functional segment, let alone the adjacent ones and the rest of the spine, the type of motion detected in dynamic testing as well as intraoperatively, the surgical policy adopted (scraping of discs, deliberately going inside the disc, mere sequestrectomy, mere foraminotomy for some harder subligamentar extrusions), etc.

We feel that, pretty much in the same manner that after an initial period of enthusiasm no long-term concluding evidence has shown that interspinous devices positively interfere with the rate of recurrence of herniated discs [2, 3, 7], we should remain vigilant regarding this new tool. The fact that interspinous devices are placed away from the dural sac and nerve roots made its safety profile rather forgiving. Even if interspinous devices failed to show any significant difference in the primary outcome and increased health expenditure, it could be argued that they implicated no manipulation of nerve structures. On the contrary, the placement of the annular closing device results in an intimate proximity to the nerve roots, making its implantation technically more demanding and increasing the risk for potential harm resulting from device displacement or failure (either mechanical, inflammatory, infectious). This should at least raise some awareness regarding an untimely precocious and diligent implementation of this technique before long-term durability and safety of this device have been categorically established.

We find ourselves at a very early stage of the adoption curve, where a tendency for enthusiasm and promotion of a new eventually promising technique is understandable. With the recent approval by the FDA for the use of this device in the US market and a subsequent post-market clinical trial [8], as well as the expected 5-year outcome reporting of this RCT, new data and insights will be brought to the table on this interesting topic. As we move forward it will also be worth checking how this device will be able to withstand 'real world' testing and reporting, as well as the maturation of the results gathered until now.

\section{References}

1. Barth M, Weiß C, Bouma GJ, Bostelmann R, Kursumovic A, Fandino J, Thomé C (2018) Endplate changes after lumbar discectomy with and without implantation of an annular closure device. Acta Neurochir 160(4):855-862

2. Floman Y, Millgram MA, Smorgick Y, Rand N, Ashkenazi E (2007) Failure of the Wallis interspinous implant to lower the incidence of recurrent lumbar disc herniations in patients undergoing primary disc excision. J Spinal Disord Tech 20(5):337-341

3. Gu H, Chang Y, Zeng S, Zheng X, Zhang R, Zhan S, Zhang Z (2018) Wallis interspinous spacer for treatment of primary lumbar disc herniation: three-year results of a randomized controlled trial. World Neurosurg 120:e1331-e1336

4. Kienzler JC, Klassen PD, Miller LE, Assaker R, Heidecke V, Fröhlich S, Thomé C, Annular Closure RCT Study Group (2019) Three-year results from a randomized trial of lumbar discectomy with annulus fibrosus occlusion in patients at high risk for reherniation. Acta Neurochir 161(7):1389-1396

5. Kuršumović A, Kienzler JC, Bouma GJ, Bostelmann R, Heggeness M, Thomé C, Miller LE, Barth M, Annular Closure RCT study group (2018) Morphology and clinical relevance of vertebral endplate changes following limited lumbar discectomy with or without boneanchored annular closure. Spine 43(20):1386-1394

6. Nanda D, Arts MP, Miller LE, Köhler HP, Perrin JM, Flüh C, Vajkoczy P (2019) Annular closure device lowers reoperation risk 4 years after lumbar discectomy. Med Devices (Auck) 12:327-335

7. Segura-Trepichio M, Martin-Benlloch A, Manuel Montoza-Nuñez J, Candela-Zaplana D, Nolasco A (2018) Lumbar disc herniation surgery with microdiscectomy plus interspinous stabilization: Good clinical results, but failure to lower the incidence of re-operation. J Clin Neurosci 51:29-34

8. Strenge KB, DiPaola CP, Miller LE, Hill CP, Whitmore RG (2019) Multicenter study of lumbar discectomy with Barricaid annular closure device for prevention of lumbar disc reherniation in US patients: A historically controlled post-market study protocol. Medicine 98(35):e16953

9. Thomé C, Klassen PD, Bouma GJ, Kuršumović A, Fandino J, Barth M, Arts M, van den Brink W, Bostelmann R, Hegewald A, Heidecke V, Vajkoczy P, Fröhlich S, Wolfs J, Assaker R, Van de Kelft E, Köhler HP, Jadik S, Eustacchio S, Hes R, Martens F, Annular Closure RCT Study Group (2018) Annular closure in lumbar microdiscectomy for prevention of reherniation: a randomized clinical trial. Spine J 18(12):2278-2287

Publisher's note Springer Nature remains neutral with regard to jurisdictional claims in published maps and institutional affiliations. 